\title{
Certified Beef Programs: What's in a Name?'
}

\section{Tracy Scheffler, Jason Scheffler, and Chad Carr ${ }^{2}$}

This publication is intended for producers, state and county faculty, and other stakeholders in the beef cattle industry.

How do you start your day every morning? What coffee do you drink and what cereal do you eat for breakfast? Chances are you know exactly what brand and type you like-or at least are willing to buy-because these product brands fulfill certain expectations. Certified beef programs, also known as branded beef programs, are much like other brands of products in that they have specifications for their products, and the name provides differentiation from others in the marketplace.

The first branded beef program, Certified Angus Beef, was established in 1978. By 2000, around 12 other programs were established. Subsequently, the number climbed to around 130; currently, there are 61 active certified beef programs (USDA 2020). Based on these numbers, several of the branded programs have not been financially viable. Regardless, the overall growth in the number of certified beef programs indicates that differentiating product through a brand name adds value compared to conventional grades.

Certified beef programs go beyond traditional marketing of carcasses by quality grades and yield grades established by USDA in the mid-1920s. The carcass grading system was developed to allow carcasses to be sorted based on the proportion of lean product (yield) and the expected palatability and eating characteristics (quality), thereby allowing the market to assign value based on consumer expectations.
Carcass grading is an optional service provided by the USDA Agricultural Marketing Service (AMS) and paid for by the packer; therefore, grading is performed if it is economically viable for the packer. For instance, at the University of Florida Meat Processing Center, all animals and carcasses are inspected for safety and wholesomeness by the USDA Food Safety Inspection Service (FSIS). However, the carcasses are not graded because the volume of product is not sufficient to justify the cost of having a USDA grader. Certified beef programs are also administered by USDA-AMS and paid for by the packer or company. These programs generally include specifications for quality and yield traits that are evaluated to determine carcass grades. However, these programs go several steps further by specifying additional carcass attributes, and they often stipulate certain live animal characteristics as well.

Table 1 shows several of the carcass characteristics specified by certified beef programs (based on "Comparison of Certified Beef Programs”) (USDA 2020).

Specifications for traits that determine quality grade (marbling and maturity) are often included as a component of certified beef programs, but several other carcass characteristics are also identified. Here is a summary of carcass quality specifications, and justification for these traits:

- Maturity: Younger animals produce more tender meat; in older animals, the connective tissue within muscle is more mature and stronger, and this increases toughness.

1. This document is AN372, one of a series of the Department of Animal Sciences, UF/IFAS Extension. Original publication date October 2021. Visit the EDIS website at https://edis.ifas.ufl.edu for the currently supported version of this publication.

2. Tracy Scheffler, assistant professor, muscle biology, Department of Animal Sciences; Jason Scheffler, research assistant professor, meat science and muscle biology, Department of Animal Sciences; and Chad Carr, associate professor, state Extension meat specialist, Department of Animal Sciences; UF/IFAS Extension, Gainesville, FL 32611.

The Institute of Food and Agricultural Sciences (IFAS) is an Equal Opportunity Institution authorized to provide research, educational information and other services

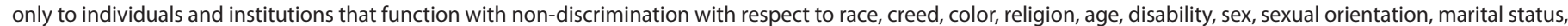

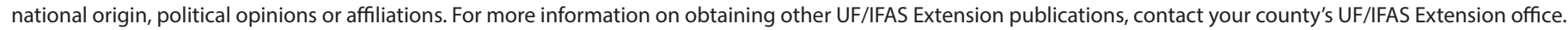
U.S. Department of Agriculture, UF/IFAS Extension Service, University of Florida, IFAS, Florida A \& M University Cooperative Extension Program, and Boards of County Commissioners Cooperating. Nick T. Place, dean for UF/IFAS Extension. 
Animals under 30 months of age are considered the most youthful or " $\mathrm{A}$ " maturity in the USDA beef quality grading standards. Previously, animal age was evaluated using skeletal and lean characteristics of the carcass; in 2017, this was changed to allow additional options (dentition or age documentation) for validation of "A" maturity (USDA 2017).

- Marbling: Marbling, or intramuscular fat (Figure 1), contributes to juiciness and flavor. Higher amounts of marbling increase the likelihood of a positive eating experience (Emerson et al. 2012; Platter et al. 2003).
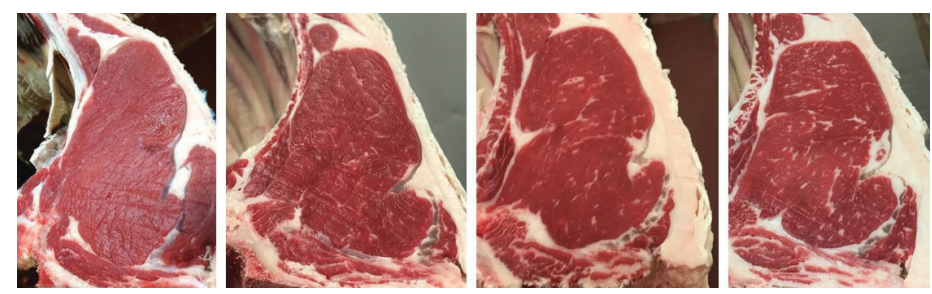

Figure 1. Intramuscular fat (marbling) in the ribeye contributes to juiciness and flavor. Images are representative of (left to right) trace, slight, small, and modest marbling. If carcasses were A maturity, these degrees of marbling would correspond to Standard, Select, Low Choice, and Average Choice (upper 2/3 Choice), respectively.

Credits: T. Scheffler and C. Carr

- Quality grade: Quality grade is determined by using the combination of maturity and marbling.

- Hump height $<2$ inches: The overwhelming majority of programs (58 of $61 ; 95 \%$ ) specify hump height less than 2 inches. This specifically targets exclusion of Bos indicus and Bos indicus-influenced cattle, such as Brahman and Brahman-influenced cattle, from certified beef programs. Beef from Bos indicus cattle exhibits greater variation in tenderness, which is largely attributed to reduced activity of the enzymes responsible for tenderization of beef during postmortem aging (Pringle et al. 1997; Whipple et al. 1990). There are Bos indicus-influenced cattle that produce tender beef. However, the economics favor excluding tender beef from Bos indicus cattle because the risk of potentially tough beef is reduced. Hump height is an easy, in-plant exclusion criterion that results in more product consistency.

- No dark cutting characteristics: As the name implies, the ribeye of these carcasses exhibits a dark reddish-purple lean color rather than the typical bright cherry red color (Figure 2). This defect is caused by changes in muscle metabolism related to long-term stress prior to slaughter; for example, heat stress may increase the incidence of dark cutting. Dark cutters exhibit variable tenderness and their color is objectionable to consumers.
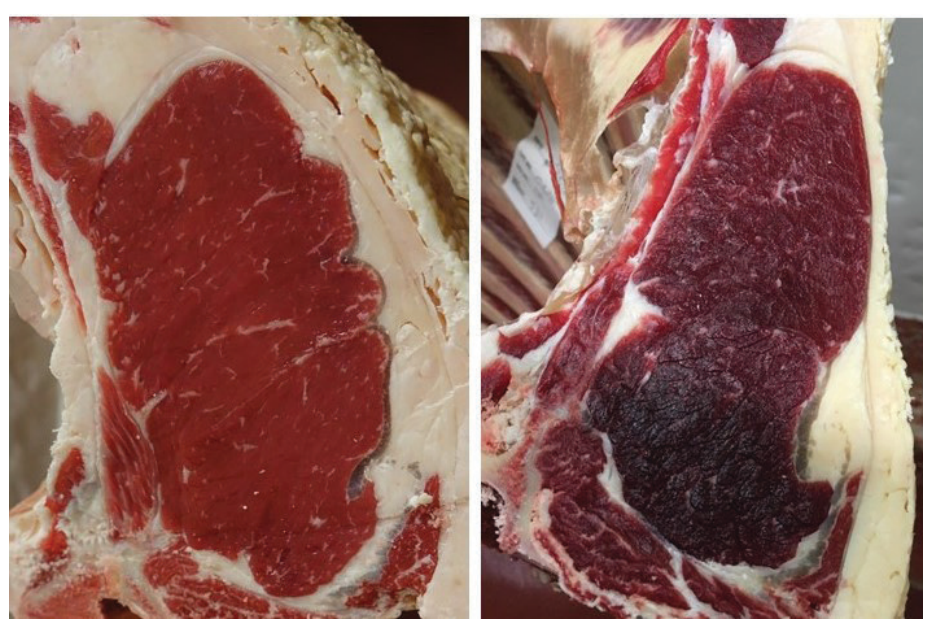

Figure 2. Variation in color of exposed ribeye. Ideally, beef is bright cherry red (left), whereas dark cutting beef (right) appears dark red to dark purplish-red.

Credits: T. Scheffler and C. Carr

- Free or practically free from capillary rupture (blood splash): A build of blood pressure in the smallest blood vessels (capillaries) can result in small hemorrhages in muscle (Figure 3). This is related to stunning at slaughter. Capillary rupture is not associated with changes in eating quality; however, exclusion from certified beef programs occurs in this case due to undesirable appearance of the lean.

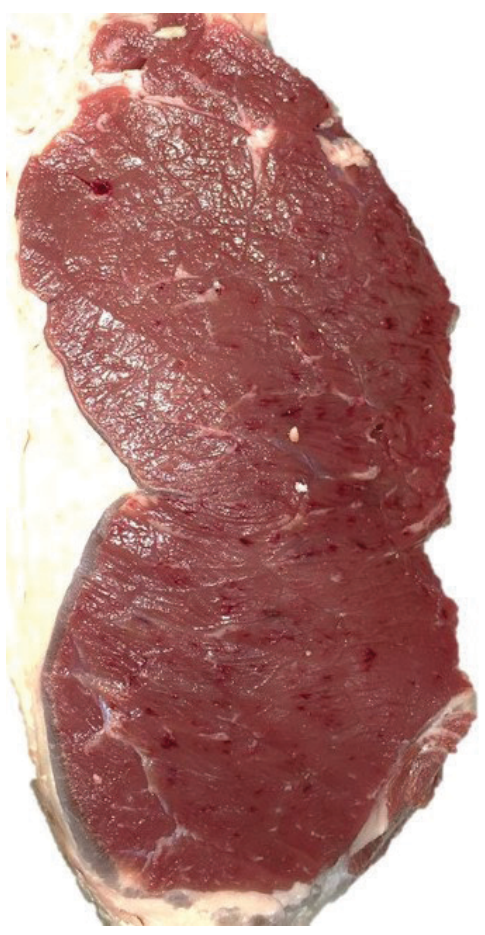

Figure 3. Capillary rupture or "blood splash" in muscle. Credits: T. Scheffler

- Marbling texture: A medium or fine marbling texture and even distribution of marbling within the lean help ensure a consistent eating experience. 
Certified beef programs may also specify requirements related to carcass yield. While these factors are not directly related to palatability, restrictions are designed to reduce seam fat (fat between muscles), and to ensure consistent portion sizes for retail and food service establishments. In general, specifications are not exclusive; they only eliminate extremes (e.g., carcasses $>1,050$ pounds). These factors include:

\section{- Hot carcass weight (HCW)}

- Ribeye area

\section{- Fat thickness}

- Yield grade: Yield grade is calculated from HCW, ribeye area, fat thickness, and percent kidney, pelvic, and heart fat.

- Muscling requirement: This stipulates moderately thick or thicker muscling and excludes carcasses exhibiting dairy-type muscling.

Certified beef programs may also require certain characteristics of the live animal (Table 2). Approximately $70 \%$ of programs require Angus phenotype, which must be a black main body with no other color behind the shoulder and above the flank. Trained USDA personnel monitor color and marking requirements for phenotype specifications. If a carcass meets a given phenotype requirement, a unique stamp is applied to the carcass at the plant to indicate eligibility for a particular program. Some programs may also require documentation of breed (genotype requirement). In this case, the animal must have identification (ear tag, tattoo, etc.) that can be traceable to registered parents and/or grandparents.

Moreover, a handful of programs have requirements related to raising and management of the live animal. Five programs specify that cattle must not have received exogenous hormones (NHTC, non-hormone treated cattle), and only one program requires that cattle have not received antibiotics, hormones, and animal by-products (NE3, "never ever" antibiotics, hormones, animal by-products). The NHTC and NE3 programs are process-verified programs that require third-party auditing and on-farm documentation. The NHTC and NE3 claims may also be used on products that are not marketed through a certified beef program.

In summary, brand names are associated with an expectation and an experience. These relate to consistency, quality, and name. It is not necessarily about having the highest quality, but meeting the consumer's expectation. This is accomplished using specifications that reduce product variability, so that the brand delivers a similar experience every time.

\section{References}

Emerson, M. R., D. R. Woerner, K. E. Belk, and J. D. Tatum. 2013. "Effectiveness of USDA Instrument-Based Measurements for Categorizing Beef Carcasses According to Differences in Longissimus Muscle Sensory Attributes." Journal of Animal Science 91:1024-1034. https://doi. org/10.2527/jas.2012-5514

Platter, W. J., J. D. Tatum, K. E. Belk, P. L. Chapman, J. A. Scanga, and G. C. Smith. 2003. "Relationships of Consumer Sensory Ratings, Marbling Score, and Shear Force Value to Consumer Acceptance of Beef Strip Loin Steaks." Journal of Animal Science 81:2741-2750. https://doi. org/10.2527/2003.81112741x

Pringle, T. D., S. E. Williams, B. S. Lamb, D. D. Johnson, and R. L. West. 1997. "Carcass Characteristics, the Calpain Proteinase System, and Aged Tenderness of Angus and Brahman Crossbred Steers." Journal of Animal Science 75:2955-2961. https://doi.org/10.2527/1997.75112955x

USDA. n.d.-a. "Daily Beef Reports." Accessed October 19, 2020. https://www.ams.usda.gov/market-news/ daily-beef-reports

USDA. n.d.-b. "Weekly and Monthly Beef Reports." Accessed October 19, 2020. https://www.ams.usda.gov/ market-news/weekly-and-monthly-beef-reports

USDA. 2017. "United States Standards for Grades of Carcass Beef." https://www.ams.usda.gov/sites/default/files/ media/CarcassBeefStandard.pdf

USDA. 2020. "USDA Certified Beef Programs." Accessed October 8, 2020. https://www.ams.usda.gov/sites/default/ files/media/LPSCertifiedBeefProgramComparison.pdf

Whipple, G., M. Koohmaraie, M. E. Dikeman, J. D. Crouse, M. C. Hunt, and R. D. Klemm. 1990. "Evaluation of Attributes That Affect Longissimus Muscle Tenderness in Bos taurus and Bos indicus Cattle." Journal of Animal Science 68:2716-2728. https://doi.org/10.2527/1990.6892716x 
Table 1. Carcass characteristics specified in USDA certified beef programs, and the number of programs that require each specification.

\begin{tabular}{|c|c|c|c|}
\hline & Carcass Characteristic & $\begin{array}{l}\text { \# Programs } \\
\text { (out of 61) }\end{array}$ & Notes \\
\hline \multirow[t]{8}{*}{ Quality grade } & Maturity $<30$ months & 58 & $\sim 95 \%$ of fed steers and heifers meet requirements. \\
\hline & Marbling (minimum amount) & & \\
\hline & Slightly abundant ${ }^{00}$ & $1^{1}$ & $\begin{array}{l}\text { Minimum marbling for Prime. Less than } 10 \% \text { of fed } \\
\text { cattle meet requirement. }\end{array}$ \\
\hline & Moderate ${ }^{00}$ & 2 & \multirow{4}{*}{$\begin{array}{l}\text { Small, modest, and moderate will grade Choice (if A } \\
\text { maturity). } \sim 70 \% \text { of fed cattle grade Choice, but only } \\
\sim 20 \% \text { are upper } 2 / 3 \text { Choice } 2 \text {, meaning they have the } \\
\text { higher amounts of marbling (Modest and Moderate). }\end{array}$} \\
\hline & Modest ${ }^{00}$ & 22 & \\
\hline & Small ${ }^{50}$ & 1 & \\
\hline & Smallo0 & 7 & \\
\hline & Slight ${ }^{00-99}$ & 28 & Eligible for USDA Select (if A maturity). \\
\hline \multirow[t]{4}{*}{ Other quality traits } & Hump height $<2$ inches & 58 & Restricts Bos indicus-influenced cattle. \\
\hline & Free of dark cutting characteristics & 55 & $\begin{array}{l}\text { Maintains desirable appearance; eliminates potential } \\
\text { variable quality. }\end{array}$ \\
\hline & Free or practically free of capillary rupture & 58 & Maintains desirable appearance. \\
\hline & Medium or fine marbling texture & 50 & Consistent eating quality. \\
\hline \multirow[t]{4}{*}{ Yield grade } & Hot carcass weight $(\mathrm{HCW})<1050 \mathrm{lb}$ & 18 & Industry average: 977 (steer), 858 (heifer) \\
\hline & Ribeye area $10-16 \mathrm{sq}$. inches & 21 & Thirty-eight do not have a specification. \\
\hline & Fat thickness $<1.0$ inch & 19 & Industry average: $0.5-0.6$ inches. \\
\hline & Yield grade $(\leq 3.9)$ & 1 & $\begin{array}{l}\text { Lower numerical yield grade is higher yielding. Fifty- } \\
\text { nine do not have a specification. }\end{array}$ \\
\hline Other & Muscling-Moderately thick or greater & 55 & Restricts dairy-type cattle. \\
\hline \multicolumn{4}{|c|}{$\begin{array}{l}{ }^{1} \text { Some programs further differentiate their product based on marbling. For example, the amount of marbling for Harris Ranch Natural Black } \\
\text { Angus } 2 \text { Diamond is slight }{ }^{40} \text { to slight }{ }^{99}, \text { while the minimum amount of marbling for Harris Ranch Natural Black Angus } 5 \text { Diamond is slightly } \\
\text { abundant }{ }^{00} \text {. } \\
{ }^{2} \text { Based on USDA National Steer \& Heifer Grading Report. Report for week ending 10/10/2020. Accessed 10/19/2020. https://www.ams.usda. } \\
\text { gov/market-news/weekly-and-monthly-beef-reports } \\
{ }^{3} \text { Based on USDA Market News, Beef Carcass Price Equivalent Index. Report for 10/16/2020. Accessed 10/19/2020. https://www.ams.usda.gov/ } \\
\text { market-news/daily-beef-reports }\end{array}$} \\
\hline
\end{tabular}

Table 2. Live animal characteristics specified in USDA certified beef programs, and the number of programs that require each specification.

\begin{tabular}{|l|l|c|l|}
\hline \multicolumn{1}{|c|}{ Live Animal Characteristic } & $\begin{array}{c}\text { \# Programs } \\
\text { (out of 58) }\end{array}$ & \multicolumn{1}{|c|}{ Notes } \\
\hline \multirow{2}{*}{ Color } & Angus phenotype & 44 & Black color \\
\cline { 2 - 4 } & Other phenotype/genotype & 5 & Includes Hereford (4) and Akaushi (1) \\
\hline \multirow{2}{*}{ Other } & Non-hormone treated (NHTC) & 5 & Process-verified program \\
\cline { 2 - 4 } & NE3-No hormones, antibiotics, and animal by-products & 1 & Process-verified program \\
\hline
\end{tabular}

